\title{
Impact of residential energy consumption on the urban heat island effect in Tainan
}

\author{
Feng-Yi Lin ${ }^{1}$, Ruey-Lung Hwang ${ }^{2}$, Tzu-Ping Lin ${ }^{2}$ \\ ${ }^{1}$ Department of Architecture National Cheng Kung University, Tainan, Taiwan \\ 2 Department of Industrial Technology Education, National Kaohsiung Normal University, \\ Kaohsiung, Taiwan
}

\begin{abstract}
The emissions of artificial waste heat have an obvious effect on an urban heat island (UHI). Taking Tainan City, Taiwan as an example, this paper uses the existing power consumption and GIS data to estimate the energy consumption information of the city's each district and employs the Morphing approach to establish the climatic data of various urban districts and to calculate long-term cumulative UHI intensity (UHII). The results show that UHII increases with energy consumption. When energy consumption exceeds $2500 \mathrm{MWh}$, the increase in UHII approaches $6900^{\circ} \mathrm{C}$-hour, meaning a limited effect of building energy consumption on UHII.
\end{abstract}

\section{Introduction}

The UHI effect increases as the urban scale expands. Under the effect of urbanization, the mean intensity of UHI of Athens now exceeds $10^{\circ} \mathrm{C}$ (Santamouris et al. 2001). The summer temperatures of cities along the Yangtze River Delta, China have risen by $0.13-0.25^{\circ} \mathrm{C}$ every 10 years; and the winter temperatures of BeijingTianjin-Hebei have risen by $0.1-0.2^{\circ} \mathrm{C}$ (Wu et al. 2013). Due to the development of new artificial islands, temperatures have gone up by $2-3^{\circ} \mathrm{C}$ in Bahrain (Radhi, 2013).

Crutzen (2004) mentioned that man-induced heat emissions have a significant potential impact on a local climate. Their sources include traffic, building and industrial consumptions, heat emissions from the energy consumption of air conditioning, and hot water and household appliances in buildings altogether account for about 2/3 of the total emissions (Sailor, 2011). Most human activities concentrate in urban areas, and population growth is coupled with an increase in maninduced heat. For example, Ignatius et al. (2016) found that residential air conditioning energy consumption in urban areas is $8 \%$ higher than that in suburbs in Singapore. Urban energy consumption has increased $32-42 \%$ in London, England (Kolokotroni, 2010). Zinzi et al. (2017) noted that the energy consumption of urban areas is $46 \%$ higher than that of suburbs in Rome, Italy. Salvati et al. (2017) indicated that the difference between urban and suburban energy consumptions is $18-28 \%$ in Barcelona, Spain. Air conditioning energy consumption of the central business district is $23-46 \%$ higher than that of suburbs in Melbourne, Australia (Chen, 2012).
The overland built environment can reflect the amount of man-induced heat emissions and urban temperature or heat island effect intensity. For example, Yeo et al. (2013), Howard et al. (2012), and Fonseca et al. (2016) used geographic information system (GIS) data to establish a distribution map of urban energy use. Ignatius et al. (2016), Wang et al. (2016), and Liao et al. (2015) used GIS data and buffer analysis to build an urban temperature regression prediction equation and utilized it to calculate the temperature of a whole city and the UHI distribution diagram.

The purpose of this study is to gather hourly meteorological data of various districts in Tainan City by gridding according to existing GIS data. We then predict residential energy consumption and analyze the relationship between the UHI effect and residential energy consumption.

\section{Methods}

\section{Study site}

In order to effectively estimate the heat island distribution in different urban areas, this study takes Tainan City center in southwest Taiwan as the subject and employs a uniform grid with mean size of $200 \mathrm{~m} \times 200 \mathrm{~m}$ to approximate a block unit, thus dividing the research scope into 1,496 grids. There are 34 measuring points for recording temperature and humidity in this region. Logpro is the instrument used by this experiment; temperature accuracy is $\pm 0.5^{\circ} \mathrm{C}$, humidity accuracy is $\pm 3 \%$, and it is installed in a climate box at $2.5 \mathrm{~m}$ above ground. The sampling interval is 15 minutes. The recording time is from April 1, 2016 to March 31, 2017. Figure 1 (A) shows the measuring point locations and the grid division. Figure 1 (B) shows the actual instrument mounting.

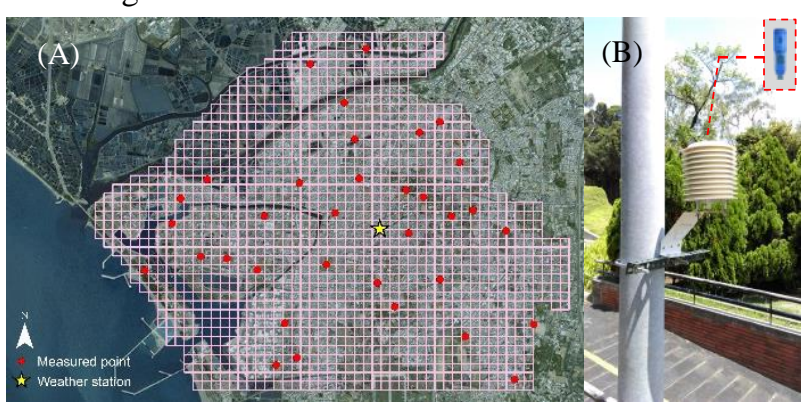

Figure 1: (A) measuring point locations and grid division, (B) actual instrument mounting. 


\section{Generate grid hourly weather data}

This study employs the Morphing approach for collecting urban grid micro-climate data. The records of Tainan's weather stations measured in the corresponding period are taken as basic reference data and integrated with 34 pieces of data to calculate the difference between each meteorological element at each measuring point and the reference point in each month. The difference methods of this approach include: (1) shift, i.e. absolute variation of weather variable; (2) linear stretch, i.e. change ratio of weather variable; when the climate change scenario cannot be represented only by an absolute variation or ratio, then (3) shift + stretch is used. The specific algorithms of outside air temperature and relative humidity are Eqs. (1)-(3):

$$
\begin{aligned}
& \mathrm{T}=\mathrm{T}_{0}+\Delta \mathrm{T}_{\mathrm{m}}+\alpha \mathrm{T}_{\mathrm{m}}\left(\mathrm{T}_{0}-\mathrm{T}_{0, \mathrm{~m}}\right) \\
& \alpha \mathrm{T}_{\mathrm{m}}=\frac{\Delta \mathrm{T}_{\text {max }, \mathrm{m}}-\Delta \mathrm{T}_{\min , \mathrm{m}}}{\mathrm{T}_{0, \text { max }, \mathrm{m}}-\mathrm{T}_{0, \mathrm{~min}, \mathrm{~m}}} \\
& \mathrm{RH}=\mathrm{RH}_{0} \times\left(1+\alpha \mathrm{RH}_{\mathrm{m}}\right)
\end{aligned}
$$

where $\mathrm{T}$ and $\mathrm{T}_{0}$ are the hourly temperatures of the city and baseline point, respectively; $\mathrm{T}_{0, \mathrm{~m}}, \mathrm{~T}_{0, \mathrm{~min}, \mathrm{~m}}$, and $\mathrm{T}_{0, \mathrm{max}, \mathrm{m}}$ are respectively the monthly mean values of air temperature, of daily maximum temperature, and of daily minimum temperature for the baseline point in month $\mathrm{m} ; \Delta \mathrm{T}_{\mathrm{m}}$, $\Delta \mathrm{T}_{\mathrm{max}, \mathrm{m}}$, and $\Delta \mathrm{T}_{\mathrm{min}, \mathrm{m}}$ are respectively the difference in the monthly mean values of air temperature, of daily maximum temperature, and of daily minimum temperature in urban areas with those in the baseline position; $\mathrm{RH}$ and $\mathrm{RH}_{0}$ correspond to the hourly relative humidity of the city and the baseline position; and $\alpha \mathrm{RH}_{\mathrm{m}}$ is the ratio of the monthly variation of the city's relative humidity to the figure of the baseline position.

Table 1: Buffer scenarios.

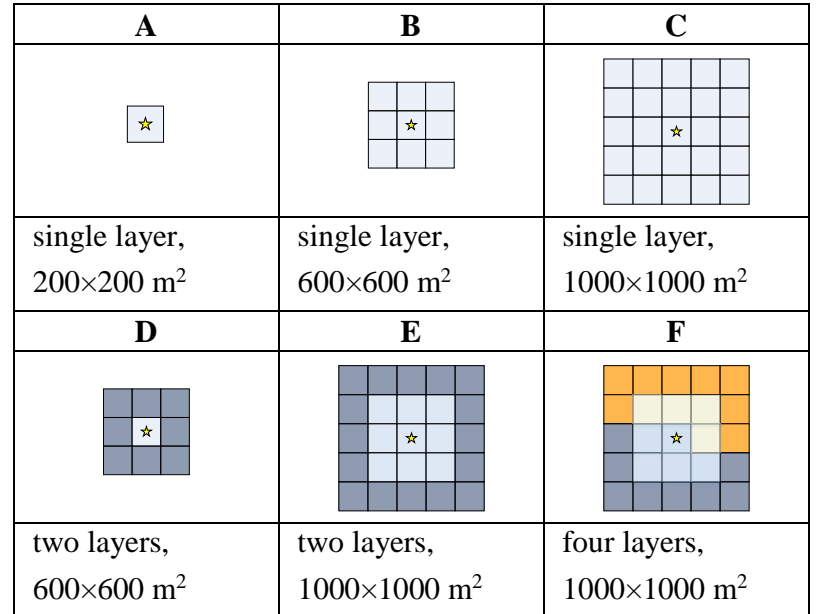

The necessary climate variables $\Delta \mathrm{T}_{\mathrm{m}}, \alpha \mathrm{T}_{\mathrm{m}}$, and $\alpha \mathrm{RH}_{\mathrm{m}}$ are derived from multiple regression analysis of the monthly mean observed by various measuring points and the variables of urban form and structure obtained from GIS information. The climate variables of each grid are predicted by establishing a regression equation, which are substituted to the Morphing approach to generate grid weather data. The problem that the temperature and humidity measuring station cannot be mounted in each grid is solved. The environmental parameters used in this study include building area, green and water areas, open area, road area, population, and average building height, and the appropriate factors are screened out by using Stepwise regression. The environmental parameters are calculated according to the $200 \mathrm{~m} \times 200 \mathrm{~m}$ basic unit, three single buffers, two double-layer buffers, and one fourlayer buffer by comparing wind direction respectively. Table 1 lists the information of various buffer scenarios.

\section{Cumulative UHII}

In order to know the temperature increments in different urban districts, UHII is an index for quantifying the outside air temperature difference between urban and rural areas. However, UHII varies with time. The present maximum temperature difference evaluation method is not completely suitable for measuring UHII variances over a period of time. Therefore, Cui et al. (2017) and Dean (2015) defined a UHII index for long-term evaluation. Its computing mode is expressed as Eq. (4).

$$
\mathrm{UHII}=\sum_{\mathrm{h}=1}^{\mathrm{H}}\left[\mathrm{T}_{\mathrm{k}, \mathrm{h}}-\min \left(\mathrm{T}_{\mathrm{k}, \mathrm{h}}, \mathrm{T}_{\mathrm{r}, \mathrm{h}}\right)\right]
$$

where, $T_{k, h}$ is the temperature of Grid $k$ at h-th hour, $T_{r, h}$ is the reference temperature of the first 5 grids of minimum temperature at h-th hour, and $H$ is the total hours of a specified period. The UHII index defined by Eq. (4) is the cumulative UHII in a specified period calculated in unit of degree-hours. Thus, the magnitude and duration of urban-rural temperature difference can be examined at the same time.

\section{Grid EUI prediction model}

As the computing scale of the existing power consumption data and population data is larger than the mesh scale, it cannot be used directly. According to the calculated grid size of weather data, the GIS data of different statistical scales, including building, land use, population, and Taiwan Power Company power consumption data, are integrated into the $200 \mathrm{~m} \times 200 \mathrm{~m}$ grid. Figure 2 presents the scale and integration method of GIS data.
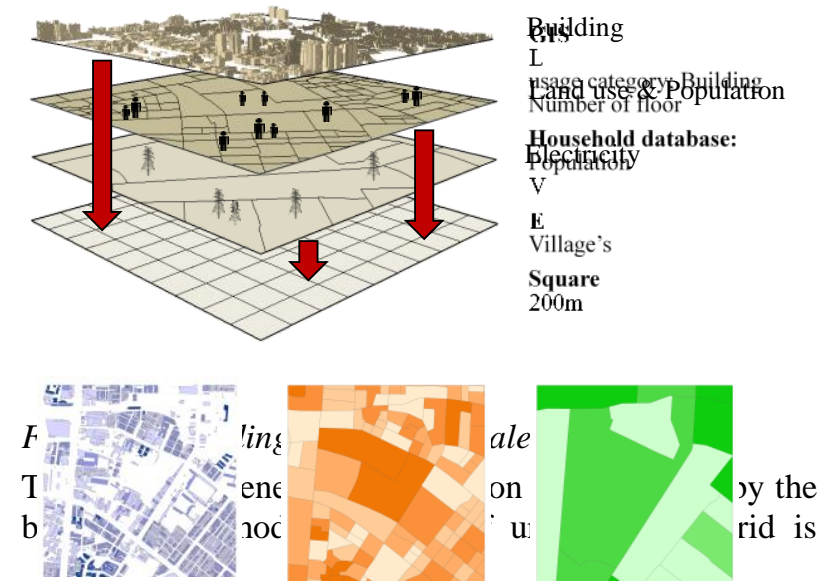
obtained by architectural dynamic energy consumption simulation. For occupant behaviors, indoor equipment and physical properties of building materials are very uncertain and difficult to be represented by a single standard model. This study uses the Monte Carlo method to generate the building model for energy consumption simulation. Table 2 shows the ranges of parameters and values; 500 building models are combined from each building type for uncertainty analysis. The building types come from the model configuration of Lin et al. (2017): (a) townhouse lower than 4 stories, (b) low-rise apartment, and (c) high-rise apartment with elevators, as shown in Figure 3. The simulation software is EnergyPlus. (a)

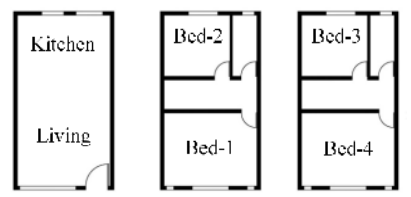

(c)

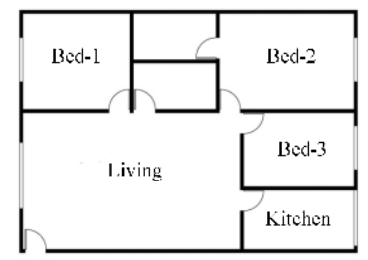

(b)

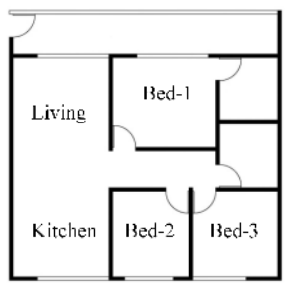

Figure 3: Floor plan of (a) townhouse, (b) low-rise apartment, and (c) apartment with elevators (Lin, 2017)

Table 2: Building model parameters and probability distribution of uncertainty analysis

\begin{tabular}{|l|c|c|c|}
\hline \multicolumn{1}{|c|}{ Item } & Unit & Mean & SD \\
\hline Household floor area* & $\mathrm{m}^{2}$ & 100 & 10 \\
\hline Concrete façade thickness* & $\mathrm{m}$ & 0.120 & 0.030 \\
\hline Façade insulation thickness* & $\mathrm{m}$ & 0.025 & 0.005 \\
\hline Concrete roof thickness* & $\mathrm{m}$ & 0.100 & 0.030 \\
\hline Roof insulation thickness* & $\mathrm{m}$ & 0.025 & 0.005 \\
\hline Window-wall-ratio* & - & 0.40 & 0.10 \\
\hline External shading depth* & $\mathrm{m}$ & 0.50 & 0.10 \\
\hline SHGC of glasses* & - & 0.60 & 0.10 \\
\hline U-value of glasses* & $\mathrm{W} / \mathrm{m}^{2} \mathrm{~K}$ & 5.5 & 0.5 \\
\hline Household lighting level* & $\mathrm{W} / \mathrm{m}^{2}$ & 10 & 3.0 \\
\hline Store lighting level* & $\mathrm{W} / \mathrm{m}^{2}$ & 20 & 4.0 \\
\hline Household appliance level* & $\mathrm{kW}$ & 15 & 3.0 \\
\hline Store appliance level* & $\mathrm{W} / \mathrm{m}^{2}$ & 550 & 110 \\
\hline COP of air-conditioner* & - & 3.0 & 0.3 \\
\hline *: Probability distribution is normal distribution & \\
\hline
\end{tabular}

When the EUI base data of various building types are obtained, the proportion of floor area (FA) of each building type can be taken as a weight coefficient to work out the EUI of each grid (EUI $\mathrm{FA}_{\mathrm{FA}}$ ) on the energy map, disregarding the population, by using Eq. (5).

$$
\mathrm{EU}_{\mathrm{FA}}=\sum_{\mathrm{k}=1}^{4} \mathrm{EUI}_{\mathrm{k}} \times \mathrm{FA}_{\mathrm{k}}
$$

In fact, the total power consumption of each neighborhood is related to the total floor area and is absolutely influenced by the neighborhood population. The resident population per $100 \mathrm{~m}^{2}$ floor area of each neighborhood, or residential density $\left(D_{o c}\right)$, can be calculated from the population statistics and building data as the corrected parameter for clarifying the effect of population on total power consumption. According to the findings of Lin et al. (2017), the residential density correction equation is Eq. (6). Grid energy consumption corrected by population density is Eq. (7).

$$
\begin{gathered}
f\left(D_{o c}\right)=0.332 \times \ln \left(D_{o c}\right)+0.628 \\
\mathrm{EU}_{\text {grid }}=\mathrm{f}\left(\mathrm{D}_{\mathrm{oc}}\right) \times \mathrm{EU}_{\mathrm{FA}}
\end{gathered}
$$

\section{Result of urban temperature}

\section{Hourly climate regression result}

According to Lin et al. (2019), in the 95\% confidence interval, only the building, road, and green and water areas are correlated after screening by forward selection (see Eq. (8)), and buffer scenario $\mathrm{F}$ has the best adjusted $\mathrm{R}^{2}$. The adjusted $\mathrm{R}^{2}$ of $\Delta \mathrm{T}_{\mathrm{m}}, \alpha \mathrm{T}_{\mathrm{m}}$, and $\alpha \mathrm{RH}_{\mathrm{m}}$ is $0.58,0.47$, and 0.39 respectively, higher than the adjusted $R^{2}$ of the other five scenarios by at most 0.31 . According to the error analysis results in Table 3, scenario $F$ has the minimum root mean square error (RMSE).

The hourly temperatures of all grids are calculated by scenario $\mathrm{F}$ according to Eq. (8). Figure 4 shows the daily hourly temperature changes of maximum, median, and minimum temperature grids. The maximum temperature grid ranges within $22-36^{\circ} \mathrm{C}$, and the minimum temperature grid ranges within $20-33^{\circ} \mathrm{C}$. The temperature difference between maximum temperature grid and minimum temperature grid is $2-3^{\circ} \mathrm{C}$.

$\Delta \mathrm{T}_{\mathrm{m}}, \alpha \mathrm{T}_{\mathrm{m}}, \alpha \mathrm{RH}_{\mathrm{m}}=\mathrm{f}$ (Building, Road, Green \& Water) (8)

Table 3: Adjusted $R^{2}$ and error analysis of various buffers

\begin{tabular}{|l|l|l|l|c|c|}
\hline \multirow{2}{*}{ Buffer } & \multicolumn{3}{|c|}{${\text { Adjusted } \mathrm{R}^{2}}^{2}$} & \multicolumn{2}{c|}{ RMSE } \\
\cline { 2 - 6 } & $\Delta \mathrm{T}_{\mathrm{m}}$ & $\alpha \mathrm{T}_{\mathrm{m}}$ & $\alpha \mathrm{RH}_{\mathrm{m}}$ & $\mathrm{Ta}$ & $\mathrm{RH}$ \\
\hline A & 0.48 & 0.19 & 0.31 & $0.6-1.0$ & $3.4-7.1$ \\
\hline B & 0.43 & 0.18 & 0.30 & $0.6-1.0$ & $3.4-6.4$ \\
\hline C & 0.27 & 0.22 & 0.26 & $0.5-1.0$ & $3.4-6.6$ \\
\hline D & 0.56 & 0.29 & 0.39 & $0.6-1.0$ & $3.3-6.2$ \\
\hline E & 0.50 & 0.48 & 0.36 & $0.7-2.5$ & $3.8-11.5$ \\
\hline F & 0.58 & 0.47 & 0.39 & $0.5-1.0$ & $3.4-6.2$ \\
\hline
\end{tabular}


(a)

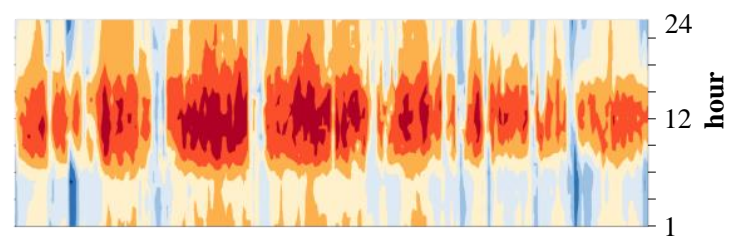

(b)

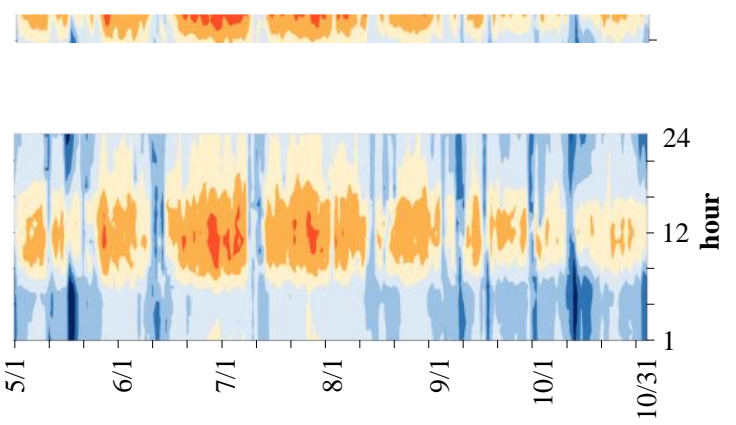

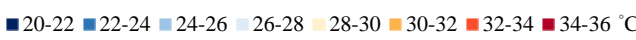

Figure 4: Hourly temperature changes of (a) maximum, (b) medium, and (c) minimum temperature grids

\section{Cumulative UHII distribution}

The distribution pattern of Tainan UHII during MayOctober is shown in Figure 5. The UHII of 3\% of grids is $8000-9500^{\circ} \mathrm{C}$-hour during May-October, and that of $22 \%$ is $6500-8000^{\circ} \mathrm{C}$-hour. These regions have high building density in Tainan, and so they have relatively high UHII. The UHII of $49 \%$ is $3500-6500^{\circ} \mathrm{C}$-hour. These regions are influenced by two factors; one is the new urban planning design, and so building density is a little lower, the ambient green area increases, and UHII drops; the other one is the university city with low building density and with a lot of green areas and open spaces. The grids with UHII lower than $3500^{\circ} \mathrm{C}$-hour have large green areas and waters; these regions are located in the suburbs.

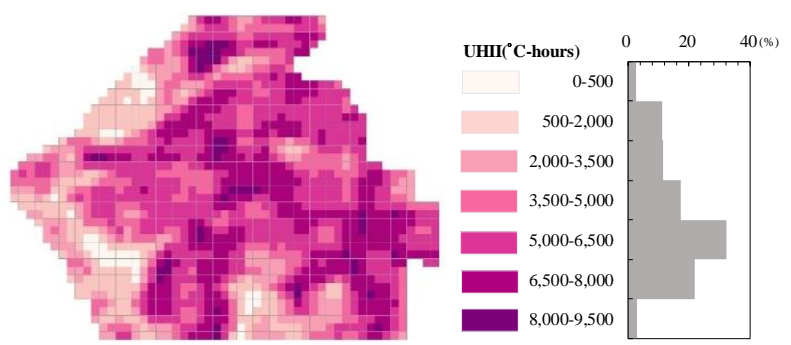

Figure 5: Cumulative UHII distribution

\section{Result of residential energy}

\section{EUI uncertainty analysis result}

Figure 6 shows the simulation results of three standard house models. The townhouse is $18.7-46.1 \mathrm{kWh} / \mathrm{m}^{2}$, the average value is $29.3 \mathrm{kWh} / \mathrm{m}^{2}$, and the standard deviation is $3.5 \mathrm{kWh} / \mathrm{m}^{2}$; the range of a low-rise apartment without an elevator is $14.6-34.6 \mathrm{kWh} / \mathrm{m}^{2}$, the average value is $25.1 \mathrm{kWh} / \mathrm{m}^{2}$, and the standard deviation is $3.5 \mathrm{kWh} / \mathrm{m}^{2}$; the range of a high-rise apartment with elevators is 24.0$52.2 \mathrm{kWh} / \mathrm{m}^{2}$, the average value is $35.7 \mathrm{kWh} / \mathrm{m}^{2}$, and the standard deviation is $5.2 \mathrm{kWh} / \mathrm{m}^{2}$. As the townhouse has a larger total area of shell, more heat is transferred to the rooms all year-round, raising energy consumption for cooling. The high-rise apartment with elevators has various public facilities that consume power, and so its energy consumption is higher than the other two types.

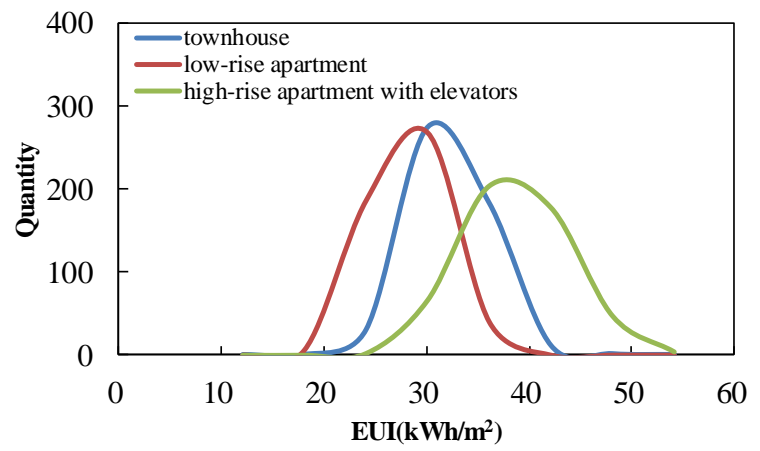

Figure 6: Simulation results of three standardized houses

\section{Energy distribution}

Figure 7 shows the urban energy use map of $200 \times 200 \mathrm{~m}$ grids of Tainan City center calculated by Eq. (2), where $37 \%$ of grids (gray grids) are non-domestic blocks, and so there is no energy consumption information. The energy consumption of $28 \%$ of grids is lower than $1000 \mathrm{MWh}$; the energy consumption of $15 \%$ is $1000-1500 \mathrm{MWh}$; the grids of the high energy consumption region $2000-2500 \mathrm{MWh}$ and larger than $2500 \mathrm{MWh}$ account for $4 \%$, respectively, most of which are in the right side of the map - highly dense residential area.
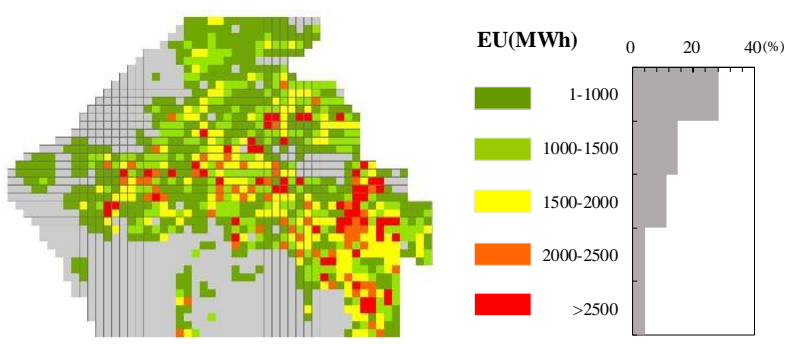

Figure 7: Urban residential energy consumption distribution

\section{Discussion}

After the grids without residential buildings (i.e. grids of 0 energy consumption) are eliminated, the other 929 grids are divided into 18 groups in ascending order of energy consumption. This study compares the effects of building energy consumptions on urban cumulative UHII, with the results shown in Figure 8. According to the comparison of residential energy consumption, UHII increases with energy consumption, but when energy consumption exceeds $2500 \mathrm{MWh}$, the increase in cumulative UHII approaches $6900^{\circ} \mathrm{C}$-hour, meaning the effect of building energy consumption on UHII is limited. Their relationship is expressed as Eq. (8).

$$
\mathrm{UHII}=6850-2670 \times \exp (-0.0012 \times \mathrm{EU})
$$




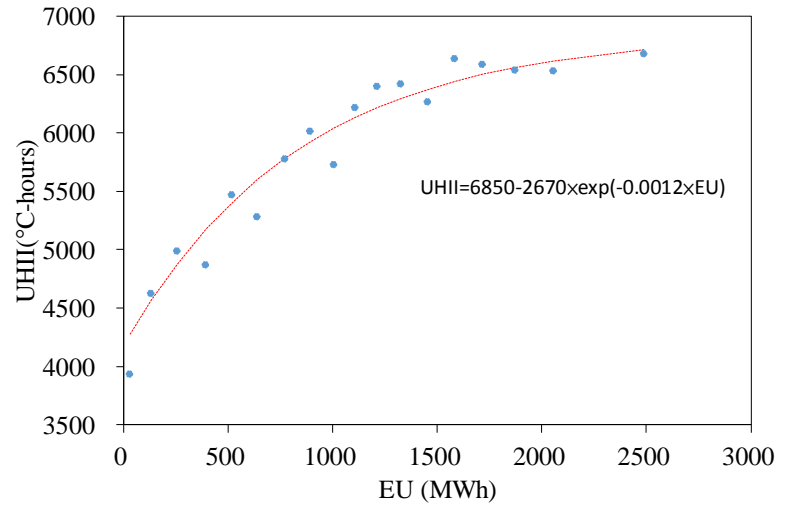

Figure 8: Effect of energy consumption on cumulative UHII

\section{Conclusion}

As urban built environments change and human activities increase, energy demand increases correspondingly. The increase in man-induced heat emissions enhances the UHI effect. This study takes Tainan City as the subject, uses a four-layer buffer scenario to find a meteorological element predictor, and employs the Morphing approach to generate grid weather data. The Monte Carlo method is also used to find out the EUI of standardized houses, while urban power consumption is calculated according to GIS data. Finally, the effect of residential power consumption during May-October on cumulative UHII is analyzed. The results are described below.

1. The maximum temperature grid ranges within 22$36^{\circ} \mathrm{C}$, and the minimum temperature grid ranges within $20-33^{\circ} \mathrm{C}$. The temperature difference between the maximum temperature grid and minimum temperature grid is $2-3^{\circ} \mathrm{C}$.

2. The cumulative UHII of $25 \%$ of grids over the regions with high building density in Tainan is higher than $6500^{\circ} \mathrm{C}$-hour; $49 \%$ of grids have more green areas under the effect of an urban planning design, and so UHII is $3500-6500^{\circ} \mathrm{C}$-hour.

3. The energy consumption of $28 \%$ of grids is lower than $1000 \mathrm{MWh}$; the energy consumption of $15 \%$ is 1000-1500 MWh; the grids of high energy consumption regions larger than $2000 \mathrm{MWh}$ account for $8 \%$.

4. UHII increases with energy consumption, but when energy consumption exceeds 2500MWh, the increase in cumulative UHII approaches $6900^{\circ} \mathrm{C}$ hour.

\section{Acknowledgement}

The authors offer their sincere appreciation for assistance through the grant provided by the Ministry of Science and Technology, Taiwan, under Project no. MOST 106-2221E-017 -013 -MY2

\section{References}

Chen, D., Ren, Z., Wang, C. H., Thatcher, M., \& Wang, X. (2012). Urban Heat Island on Australian Housing
Energy Consumption. In Proceedings of Healthy Buildings.

Crutzen, P.J. (2004). The growing urban heat and pollution"island" effect-impact on chemistry and climate. AtmosphericEnvironment 38, 3539-3540.

Cui, Y., Yan, D., Hong, T., \& Ma, J. (2017). Temporal and spatial characteristics of the urban heat island in Beijing and the impact on building design and energy performance. Energy, 130, 286-297.

Dean, W. (2015). Creating and Mapping an Urban Heat Island Index for California.

Fonseca, J. A., Nguyen, T. A., Schlueter, A., \& Marechal, F. (2016). City Energy Analyst (CEA): Integrated framework for analysis and optimization of building energy systems in neighborhoods and city districts. Energy and Buildings, 113, 202-226.

Howard, B., Parshall, L., Thompson, J., Hammer, S., Dickinson, J., \& Modi, V. (2012). Spatial distribution of urban building energy consumption by end use. Energy and Buildings, 45, 141-151.

Ignatius, M., Wong, N. H., \& Jusuf, S. K. (2016). The significance of using local predicted temperature for cooling load simulation in the tropics. Energy and Buildings, 118, 57-69.

Kolokotroni, M., Davies, M., Croxford, B., Bhuiyan, S., \& Mavrogianni, A. (2010). A validated methodology for the prediction of heating and cooling energy demand for buildings within the Urban Heat Island: Case-study of London. Solar Energy, 84(12), 22462255.

Liao, F. C., Cheng, M. J., \& Hwang, R. L. (2015). Influence of urban microclimate on air-conditioning energy needs and indoor thermal comfort in houses. Advances in Meteorology, 2015.

Lin, F. Y., Lin, T. P., \& Hwang, R. L. (2017). Using geospatial information and building energy simulation to construct urban residential energy use map with high resolution for Taiwan cities. Energy and Buildings, 157, 166-175.

Lin, F. Y., Huang, K. T., Lin, T. P., \& Hwang, R. L. (2019). Generating hourly local weather data with high spatially resolution and the applications in bioclimatic performance. Science of The Total Environment, 653, 1262-1271.

Radhi, H., Fikry, F., \& Sharples, S. (2013). Impacts of urbanisation on the thermal behaviour of new built up environments: A scoping study of the urban heat islandin Bahrain. Landscape and Urban Planning, 113, 47-61.

Sailor, D. J. (2011). A review of methods for estimating anthropogenic heat and moisture emissions in the urban environment. International Journal of Climatology, 31(2), 189-199.

Salvati, A., Roura, H. C., \& Cecere, C. (2017). Assessing the urban heat island and its energy impact on 
residential buildings in Mediterranean climate: Barcelona case study. Energy and Buildings, 146, 3854.

Santamouris, M., Papanikolaou, N., Livada, I., Koronakis, I., Georgakis, C., Argiriou, A., \& Assimakopoulos, D. N. (2001). On the impact of urban climate on the energy consumption of buildings. Solar energy, 70(3), 201-216.

Wang, Y., Berardi, U., \& Akbari, H. (2016). Comparing the effects of urban heat island mitigation strategies for Toronto, Canada. Energy and Buildings, 114, 2-19.

Wu, K., \& Yang, X. (2013). Urbanization and heterogeneous surface warming in eastern China. Chinese Science Bulletin, 58(12), 1363-1373.
Yeo, I. A., Yoon, S. H., \& Yee, J. J. (2013). Development of an urban energy demand forecasting system to support environmentally friendly urban planning. Applied Energy, 110, 304-317.

Zinzi, M., \& Carnielo, E. (2017). Impact of urban temperatures on energy performance and thermal comfort in residential buildings. The case of Rome, Italy. Energy and Buildings, 157, 20-29. 